Screening Quality Assurance Team for providing accurate cost and screening data.

Contributors: EF initiated the project. AT and CW collated screening and epidemiological data. RB, HK, and PW did the simulation analysis. AS collated and analysed economic data. Al authors participated in consultations on study design and the interpretation of the findings. RB, AT, and CW wrote the paper with input from all members of the project team. $\mathrm{RB}$ is guarantor of the work.

Funding: NHS Breast Screening Programme on behalf of the National Advisory Committee on Breast Cancer Screening. Conflict of interest: None.

1 Forrest APM. Report to the health ministers of England, Wales, Scotland and Northern Ireland by a working group chaired by Sir Patrick Forrest. London: HMSO, 1987

2 van Oortmarssen GJ, Habbema JD, van der Maas PJ, de Koning HJ, Collette $\mathrm{HJ}$, Verbeek AL, et al. A model for breast cancer screening. Cancer 1990;66:1601-12.

3 de Koning HJ, Boer R, Warmerdam PG, Beemsterboer PM, van der Maa PJ. Quantitative interpretation of age-specific mortality reductions from the Swedish breast cancer-screening trials. J Natl Cancer Inst 1995;87:1217-23.

4 Chamberlain J, Moss SM, Kirkpatrick AE, Michell M, Johns L. NHS breast screening programme results for 1991-2 [published correction appears in BMJ 1993;307:543]. BMJ 1993;307:353-6.

5 Street AD, Posnett J, Threlfall AG, Woodman CBJ, Twelves E, Friedman EHI, et al. Economic evaluation of proposed changes to the breast screening programme. York: York Health Economics Consortium, University of York, 1996. (Report P20/03.)

6 Scottish Cancer Therapy Network. Scottish breast cancer audit 1987 and 1993. Report to the chief scientist and CRAG. Edinburgh: Scottish Cancer Therapy Network, 1996

7 Brown ML, Fintor L. Cost-effectiveness of breast cancer screening preliminary results of a systematic review of the literature. Breast Cancer Res Treat 1993;25:113-8.

8 de Koning HJ, van Ineveld BM, van Oortmarssen GJ, de Haes JC, Collette $\mathrm{HJ}$, Hendriks JH, et al. Breast cancer screening and cost-effectiveness; policy alternatives, quality of life considerations and the possible impact of uncertain factors. Int J Cancer 1991;49:531-7.

9 van Ineveld BM, van Oortmarssen GJ, de Koning HJ, Boer R, van de Maas PJ. How cost-effective is breast cancer screening in different EC countries? Eur J Cancer 1993;12:1663-8.

10 Beemsterboer PM, de Koning HJ, Warmerdam PG, Boer R, Swart F, Dierks ML, et al. Prediction of the effects and costs of breast-cancer screening in Germany. Int J Cancer 1994;58:623-8.

11 Paci E, Boer R, Zappa M, de Koning HJ, van Oortmarssen GJ, Crocetti F et al. A model-based prediction of the impact on reduction in mortality by a breast cancer screening programme in the city of Florence, Italy. Eu J Cancer 1995;3:348-53.

(Accepted 20 March 1998)

\title{
Safety and toxicity of amphotericin B in glucose $5 \%$ or intralipid $20 \%$ in neutropenic patients with pneumonia or fever of unknown origin: randomised study
}

Patrick Schöffski, Mathias Freund, R Wunder, D Petersen, C H Köhne, H Hecker, U Schubert, A Ganser

\begin{abstract}
Objective: To compare the feasibility of treatment, safety, and toxicity of intravenous amphotericin B deoxycholate prepared in either glucose or intralipid for empirical antimycotic treatment of neutropenic cancer patients.

Design: Single centre stratified, randomised non-blinded phase II study.

Setting: University hospital providing tertiary clinical care.

Subjects: 51 neutropenic patients (leukaemia (35), lymphoma (11), solid tumours (5)) with refractory fever of unknown origin (24) or pneumonia (27). Interventions: Amphotericin B $0.75 \mathrm{mg} / \mathrm{kg} /$ day in $250 \mathrm{ml}$ glucose $5 \%$ solution or mixed with $250 \mathrm{ml}$ intralipid $20 \%$, given on eight consecutive days then alternate days, as a 1-4 hour infusion.

Main outcome measures: Feasibility of treatment, subjective tolerance (questionnaire), and objective toxicity (common toxicity criteria of the National Cancer Institute).

Results: Study arms were balanced for age, sex, underlying malignancy, renal and liver function, and pre- and concomitant treatment with antibiotics and nephrotoxic agents. No statistically significant or clinically relevant differences were found between the treatment groups for: daily or cumulative dose and duration of treatment with amphotericin $\mathrm{B}$; incidence and time of dose modifications or infusion duration changes related to toxicity; dose or duration of symptomatic support with opiates, antipyretics, or
\end{abstract}

antihistamines; renal function; subjective tolerance; most common toxicity scores; course of infection; and incidence of treatment failures. Patients treated with amphotericin $\mathrm{B}$ in intralipid were given fewer diuretics $(\mathrm{P}<0.05)$ and therefore had more peripheral oedema $(\mathrm{P}<0.01)$ and needed less potassium supplementation $(\mathrm{P}<0.05)$ than patients given amphotericin in glucose. Acute respiratory events were more common in the intralipid arm $(\mathrm{P}<0.05)$. Conclusions: Amphotericin B $0.75 \mathrm{mg} / \mathrm{kg} /$ day in intralipid given on eight consecutive days then alternate days provides no benefit and is associated with potential pulmonary side effects possibly because of fat overload or an incompatibility of the two drugs.

\section{Introduction}

Amphotericin B is regarded as the agent of choice for treatment of life threatening mycoses in neutropenic patients because of its broad antimycotic activity. ${ }^{1}$ It is conventionally given intravenously in glucose $5 \%$, as a colloidal suspension with the detergent sodium deoxycholate. Amphotericin B is associated with a high incidence of renal toxicity, potassium loss, fever, and chills. Attempts have been made to overcome its dose limiting renal toxicity. ${ }^{2}$ Well tolerated, highly expensive liposomal formulations are commercially available, and can be used in patients developing renal toxicity after exposure to amphotericin B deoxycholate.

Non-liposomal lipid emulsions are also known to reduce toxic effects of amphotericin in vitro and in vivo and have been given to patients. $^{3-11}$ Intralipid, a
Department of Haematology/Oncology, Hanover University Medical School, D-30625 Hanover, Germany

Patrick Schöffski, physician

R Wunder,

physician

U Schubert,

documentation

assistant

A Ganser, professor of medicine

Department of Clinical Chemistry D Petersen, physician

Biometrical Department

H Hecker, professor of biometric. Department of Haematology/Oncology, Rostock University, D-18055 Rostock, Germany

Mathias Freund, professor of medicine C H Köhne, physician

Correspondence to: Dr Schöffski Patrick_Schoffski@ compuserve.com

BMJ 1998;317:379-84 
solution of soya bean oil, phosphatidylcholine, glycerol, and water, has shown promise as a carrier for amphotericin, and in clinical trials has been observed to reduce some side effects associated with amphotericin. ${ }^{8}{ }^{12-14}$ We carried out a prospective randomised phase II trial to determine the safety and toxicity of amphotericin in glucose $5 \%$ or intralipid $20 \%$ in neutropenic cancer patients with either fever of unknown origin or pneumonia.

\section{Subjects and methods}

Patient selection criteria-Neutropenic cancer patients with pulmonary infiltrates or patients with refractory fever of unknown origin during treatment with broad spectrum antibiotics qualified for the trial. Empirical amphotericin was given to high risk patients not being treated with antifungal agents within seven days before entry to the study.

Randomisation and stratification-Patients were stratified according to presence of refractory fever of unknown origin or pneumonia, and underlying malignancy, then block randomised for treatment with amphotericin in either glucose or intralipid.

Baseline and follow up examinations-All patients underwent a standardised clinical evaluation including radiography, ultrasonography, blood counts, serum analyses, microbiology, and serology. Bronchoscopy was done whenever possible.

Treatment-Amphotericin in glucose was prepared as recommended by the manufacturer (Bristol-Myers Squibb, Munich, Germany), and amphotericin in intralipid as described. ${ }^{13}$ Amphotericin was dissolved in glucose 5\% (10 mg amphotericin/ml) then mixed with $250 \mathrm{ml}$ intralipid 20\% (Kabi-Pharmacia, Erlangen, Germany) and infused without delay. The non-blinded infusions were prepared and given in a uniform manner. Both arms had the same amphotericin dose and schedule $(0.75 \mathrm{mg} / \mathrm{kg} /$ day for eight days then alternate days). Dose escalation was prohibited, but the infusion duration could be prolonged from 1-4 hours.

Concurrent treatment-Piperacillin or third generation cephalosporins plus aminoglycosides were given as first line treatment and changed to an imipenem and glycopeptide combination in patients with refractory infections after three days. ${ }^{15}$ Amphotericin was part of the first line treatment in patients with pulmonary infiltrates. Patients with refractory fever of unknown origin received amphotericin from the fourth day. The concomitant use of 5-flucytosine was allowed. Opioids, antihistamines, or antiemetics were not given before the first dose, growth factors were not routinely given, and granulocyte transfusions were not given.

Assessment of feasibility and toxicity-The feasibility of treatment was evaluated with the protocol compliance, incidence of infusion duration changes or delays related to toxicity, and use of supportive drugs. A standardised questionnaire was completed by the patients on days $0,1,4$, and 8 , assessing 16 subjective side effects. Objective toxicities were evaluated according to modified criteria of the National Cancer Institute.

Assessment of efficacy-The patients were treated empirically without proof of systemic mycosis, and received a variety of concomitant antimicrobial agents.
Table 1 Baseline patient characteristics at study entry (data are numbers of patients unless stated otherwise)

\begin{tabular}{lcc} 
& $\begin{array}{c}\text { Amphotericin } \mathbf{B} \text { in } \\
\text { glucose } \mathbf{5 \%}\end{array}$ & $\begin{array}{c}\text { Amphotericin } \mathbf{B} \text { in } \\
\text { intralipid 20\% }\end{array}$ \\
\hline Patients & 24 & 27 \\
\hline Mean age (years) (range) & $45(18-66)$ & $42(19-71)$ \\
\hline Sex: & & 20 \\
\hline Male & 15 & 7 \\
\hline Female & 9 & 18 \\
\hline Malignancy & & 5 \\
\hline Leukaemia & 17 & 4 \\
\hline Lymphoma & 6 & 10 \\
\hline Solid tumours & 1 & 17 \\
\hline Infection & & 10 \\
\hline Fever of unknown origin & 14 & 7 \\
\hline Pneumonia: & 10 & \\
\hline Unilateral infiltrates & 6 & \\
\hline Bilateral infiltrates & 4 & \\
\hline
\end{tabular}

The study was thus not designed to determine antifungal efficacy, but to re-evaluate the feasibility of treatment with amphotericin and intralipid and its safety and toxicity.

Study ethics-The protocol was approved by our ethics committee and performed according to the Declaration of Helsinki. All patients gave their informed consent.

Statistics-The trial's design was based on a prior power calculation for the endpoints of serum creatinine concentration and creatinine clearance. The possible difference between the study arms was estimated from the literature. ${ }^{12}$ We planned to randomise 50 patients for each arm, to achieve a power of $90 \%$ for the detection of an effect size of $\delta=\mathrm{d} / \mathrm{s}=0.667$ when applying a two sided $t$ test at the $5 \%$ level. For creatinine clearance, this corresponds to a difference of $\mathrm{d}=20 \mathrm{ml} / \mathrm{min}$ between the treatments assuming a $\mathrm{SD}$ of $\mathrm{s}=30 \mathrm{ml} / \mathrm{min}$ within each group. After observation of severe side effects not previously reported, we performed a non-scheduled interim analysis of toxicity data resulting in premature termination of the trial for patient safety. With the sample size $(n=51)$ the minimal effect size under the same conditions is $\delta=\mathrm{d} / \mathrm{s}=0.93$. Discrete variables were compared by $\chi^{2}$ analysis, Mantel-Haenszel, or Fisher's exact test depending on the expected frequencies, and continuous variables were compared with a two sample $t$ test or Mann-Whitney $\mathrm{U}$ test depending on the skewness. A $\mathrm{P}$ value of $<0.05$ was considered significant (table 1).

\section{Results}

Twenty four patients were randomised to receive amphotericin in glucose and 27 to receive amphotericin in intralipid. The study arms were balanced for age, sex, malignancy, and all relevant laboratory values at baseline (table 1). The concurrent use of nephrotoxic and antimicrobial agents including 5-flucytosine was identical in both arms; opiates, antipyretics, and antihistamines were required in comparable dosages irrespective of treatment assignment (data not shown). Prednisolone was used significantly more in the glucose arm as part of the anticancer treatment (mean cumulative dose 285 (SD 479.0) versus 95 (155.8) mg; $\mathrm{P}=0.007, t$ test) 


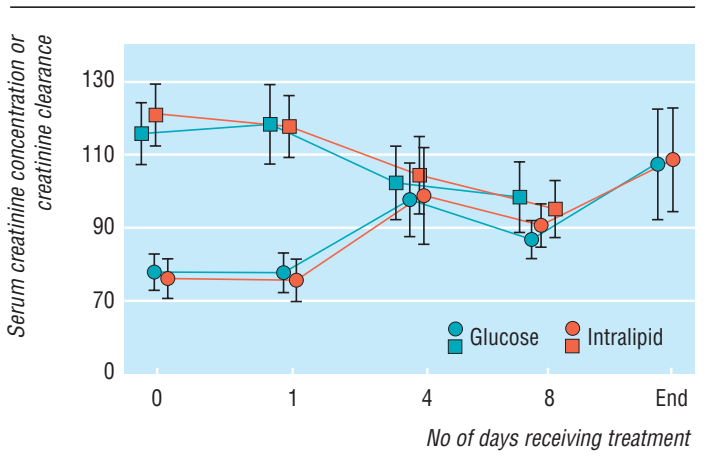

Mean (SE) values for creatinine clearance (normal range $80-170 \mathrm{ml} / \mathrm{min}$ ) (two upper curves) and serum creatinine concentration (50-80 $\mu \mathrm{mol} / \mathrm{l})$ (two lower curves) in patients treated with amphotericin B in glucose $5 \%(n=24)$ or intralipid 20\% $(n=27)$ (differences between two randomisation arms not significant)

The daily and cumulative dose of amphotericin, overall duration of treatment, incidence of infusion duration changes, or dose reductions due to toxicity were not significantly different (table 2). The study arms were balanced for sodium chloride supplementation known to be capable of preventing renal toxicity; the sodium content of all drugs was taken into account (data not shown).

Renal tubular damage was obvious in both groups Mean serum potassium concentration fell uniformly during the course of amphotericin treatment irrespective of treatment assignment (data not shown). The patients were efficiently supplemented. The cumulative potassium requirement was significantly lower in the intralipid arm (1750 (1480) versus 1194 (972) mmol; $\mathrm{P}=0.037$ ). This observation was related to unexplained differences in the use of frusemide (furosemide) (59.4 (18.0) versus 19.0 (21.9) $\mathrm{mg} /$ day; $\mathrm{P}=0.028)$. Peripheral oedema was therefore noted more often in the intralipid group ( $\mathrm{P}=0.009$, Mantel-Haenszel $\chi^{2}$ test). Complications possibly related to electrolyte imbalance, such as arrhythmia, were rare and occurred in three controls and six patients treated with the lipid emulsion.

Effects of amphotericin on renal function were evident (fig). Compared with baseline, serum creatinine and blood urea nitrogen concentrations increased during the course of treatment. Significant differences between the study arms, however, were not found for any of the variables of renal function (table 3 ; data for blood urea nitrogen concentration not shown). Four patients-one in the control group and three in the experimental arm-had severe renal dysfunction. One patient in the conventional group and two patients in the intralipid group underwent haemodialysis. Clogging of the dialysis membranes, possibly related to hyperlipidaemia, occurred repeatedly in the two patients in the intralipid group.

Aspartate transaminase concentration was mildly elevated and significantly higher in the glucose group throughout treatment (mean 17.9 (16.0) versus 10.0 (5.1) $\mathrm{U} / 1 ; \mathrm{P}=0.028, t$ test). No differences were noted for alanine transaminase or bilirubin concentrations (data not shown). Liver dysfunction was not clinically evident.

Other non-haematological toxicities occurred frequently in both groups-most were related to the use of
Table 2 Administration of amphotericin B

\begin{tabular}{lrr} 
& $\begin{array}{c}\text { Amphotericin B } \\
\text { in glucose 5\% }\end{array}$ & $\begin{array}{c}\text { Amphotericin B in } \\
\text { intralipid 20\% }\end{array}$ \\
\hline Dose (mean) (SD): & & \\
\hline Absolute (mg/day) & $43.8(9.0)$ & $47.7(9.0)$ \\
\hline Relative (mg/kg/day) & $0.7(0.1)$ & $0.7(0.1)$ \\
\hline Cumulative (mg) & $513.3(260.0)$ & $489.0(320.0)$ \\
\hline Treatment duration (mean) (SD): & $15.8(9.1)$ & $13.8(8.8)$ \\
\hline Days on study & $11.3(5.2)$ & $9.9(5.1)$ \\
\hline Treatment days & & \\
\hline Incidence of toxicity related schedule modifications (No of patients): & 17 & 15 \\
\hline Prolongation of infusion duration & 6 & 4 \\
\hline Dose reduction & & \\
\hline
\end{tabular}

amphotericin, and others to the underlying malignancy and its treatment (table 4). Common grade 1-2 toxicities were chills, fever, and sweating. These occurred in up to $69 \%$ of patients and showed little difference between the study arms. Severe grade 3-4 toxicity was not uncommon, and discomfort and dyspnoea were the most frequent observations. A variety of renal, gastrointestinal, cardiovascular, and respiratory toxicities were documented. These were evenly distributed in both study arms, the exception being acute pulmonary events.

Eleven patients in the glucose group (four with refractory fever of unknown origin and seven with pneumonia) and 17 patients in the intralipid group (five with refractory fever of unknown origin and 12 with pneumonia) had pulmonary symptoms. Three patients in the glucose group and two in the experimental group had grade 1-2 dyspnoea. Grade 3-4 acute dyspnoea occurred in four control patients and in 11 patients in the intralipid group $(\mathrm{P}=0.083$, Mantel-Haenszel test). Mild coughing was present in nine and 13 patients respectively, and grade 3-4 coughing was observed in one patient in each group. Other pulmonary events (eg, respiratory pain, pleuritis, fibrosis, adult respiratory distress syndrome, respirator treatment) occurred in one patient in the conventional arm and in eight patients in the intralipid group (graded 3-4 in one glucose patient and five intralipid patients; $\mathrm{P}=0.029$, Mantel-Haenszel test).

We repeatedly observed acute respiratory distress after initiation of the lipid infusion, sometimes associated with coughing, tachypnoea, agitation, cyanosis, and deterioration of oxygen saturation. Pulmonary events occurred when amphotericin in intralipid was repeatedly given to patients with either

\begin{tabular}{lcc}
\hline $\begin{array}{l}\text { Table 3 Renal function } \\
\text { Variable }\end{array}$ & $\begin{array}{c}\text { Amphotericin B in } \\
\text { glucose 5\% }\end{array}$ & $\begin{array}{c}\text { Amphotericin B in } \\
\text { intralipid 20\% }\end{array}$ \\
\hline \begin{tabular}{l} 
Serum creatinine concentration (mean) (SD; normal range $\mathbf{5 0 - 8 0 ~} \boldsymbol{\mu m o l} / \mathbf{l})$ \\
\hline Day:
\end{tabular} \\
\hline 0 & $75.1(23.7)$ & $76.5(27.4)$ \\
\hline 4 & $94.6(43.7)$ & $99.3(67.6)$ \\
\hline 8 & $85.1(22.8)$ & $90.3(25.7)$ \\
\hline Last & $105.9(73.6)$ & $109.1(72.2)$ \\
\hline Mean & $85.6(31.3)$ & $89.4(38.8)$ \\
\hline Maximum & $117.1(65.5)$ & $130.6(76.7)$ \\
\hline Creatinine clearance (mean) (SD; normal range 80-170 $\mathbf{~ m l / m i n ) ~}$ \\
\hline Day: & & \\
\hline 0 & $116.0(40.5)$ & $120.6(42.4)$ \\
\hline 4 & $103.5(45.2)$ & $104.7(48.8)$ \\
\hline 8 & $99.1(43.7)$ & $96.3(35.9)$ \\
\hline
\end{tabular}


Table 4 Evaluation of maximum non-haematological toxicity per patient based on questionnaire data and physician toxicity ratings according to modified common toxicity criteria of National Cancer Institute (grade 1-2=mild to moderate, grade 3-4=severe or life threatening events)

\begin{tabular}{|c|c|c|c|c|c|c|}
\hline \multirow[b]{2}{*}{ Variable } & \multicolumn{2}{|c|}{ Grade 0} & \multicolumn{2}{|c|}{ Grade 1-2 } & \multicolumn{2}{|c|}{ Grade 3-4 } \\
\hline & Glucose & Lipid & Glucose & Lipid & Glucose & Lipid \\
\hline Bilirubin & 14 & 15 & 4 & 6 & 5 & 4 \\
\hline Aspartate transaminase & 11 & 19 & 12 & 6 & 0 & $0^{*}$ \\
\hline Alanine transaminase & 10 & 18 & 10 & 5 & 3 & 2 \\
\hline Creatinine & 12 & 10 & 11 & 13 & 0 & 2 \\
\hline Proteinuria & 17 & 16 & 5 & 8 & 0 & 0 \\
\hline Haematuria & 7 & 12 & 15 & 12 & 0 & 0 \\
\hline BUN concentration & 8 & 11 & 12 & 13 & 3 & 1 \\
\hline Hypokalaemia & 13 & 15 & 10 & 10 & 0 & 0 \\
\hline Nausea & 1 & 6 & 16 & 11 & 3 & 4 \\
\hline Vomiting & 5 & 9 & 12 & 12 & 4 & 4 \\
\hline Diarrhoea & 5 & 10 & 13 & 8 & 3 & 6 \\
\hline Anorexia & 5 & 5 & 6 & 9 & 6 & 7 \\
\hline Headache & 7 & 13 & 11 & 9 & 2 & 0 \\
\hline Dysuria & 16 & 21 & 3 & 0 & 0 & 1 \\
\hline Urge & 14 & 17 & 5 & 4 & 0 & 1 \\
\hline Renal (other) & 20 & 20 & 1 & 0 & 0 & 3 \\
\hline Renal failure & 22 & 21 & 0 & 0 & 1 & 3 \\
\hline Weight gain & 20 & 20 & 2 & 4 & 1 & 1 \\
\hline Weight loss & 19 & 21 & 4 & 3 & 0 & 0 \\
\hline Oedema & 18 & 11 & 3 & 8 & 0 & $3^{\star *}$ \\
\hline Dyspnoea & 13 & 10 & 3 & 2 & 4 & 11 \\
\hline Cough & 11 & 9 & 9 & 13 & 1 & 1 \\
\hline Lung (other) & 19 & 14 & 0 & 3 & 1 & $5^{\star}$ \\
\hline Arrhythmia & 19 & 18 & 2 & 3 & 1 & 3 \\
\hline Hypertension & 16 & 20 & 4 & 2 & 2 & 3 \\
\hline Hypotension & 20 & 23 & 0 & 1 & 2 & 1 \\
\hline Vertigo & 13 & 16 & 6 & 5 & 1 & 1 \\
\hline Skin & 17 & 17 & 3 & 5 & 1 & 3 \\
\hline Fever (no infection) & 5 & 7 & 14 & 17 & 3 & 1 \\
\hline Chills & 4 & 8 & 18 & 17 & 0 & 0 \\
\hline Myalgia & 11 & 14 & 9 & 7 & 0 & 0 \\
\hline Sweating & 5 & 3 & 13 & 18 & 0 & 0 \\
\hline Discomfort & 3 & 0 & 8 & 12 & 10 & 10 \\
\hline
\end{tabular}

BUN=blood urea nitrogen.

${ }^{\star} \mathrm{P}<0.05$ two sided $\chi^{2}$ test, Mantel-Haenszel test.

${ }^{\star *} \mathrm{P}<0.01$ two sided $\chi^{2}$ test, Mantel-Haenszel test.

pneumonia or fever of unknown origin, with either one or four hour infusions. This toxicity seemed unrelated to pre-existing pulmonary conditions, state of infection, or extent of infiltrates, and was not attributable to the use of specific agents or possible predisposing factors such as fluid overload. The events were evaluated with bedside tests and radiography, and treated with discontinuation of the infusion, oxygen supplementation, and monitoring of vital signs. The events were of sudden onset and reversible in minutes or hours. We were not able to perform specific pulmonary function tests, bronchoscopy, or biopsy to elucidate this toxicity because of the poor condition of the neutropenic and thrombocytopenic patients and the acute, self limiting nature of the events. The patients' case records and radiological findings were reviewed in detail without showing further information. We stopped amphotericin and intralipid treatment early in two patients because of pulmonary events.

Pulmonary biopsy showed two cases of invasive candidiasis in each study arm, which were diagnosed during treatment. Six deaths related to cancer or chemotherapy occurred in the glucose group, none attributable to proved mycotic infection. Three of the four patients who died in the intralipid group had respiratory failure-one due to pulmonary candidiasis and one due to multiorgan aspergillosis-otherwise, the course of infection and incidence of treatment failures were identical in both arms.

\section{Discussion}

Systemic mycotic infections are a major threat to immunocompromised individuals because of their increasing incidence and high mortality. ${ }^{16}$ The current strategy for prevention and treatment of these infections in neutropenic patients is based on the early empirical use of toxic antifungal agents such as amphotericin.

Our study was initiated in 1993 when randomised trials suggested that amphotericin and intralipid combined was less toxic and better tolerated than conventional amphotericin (table 5). We tried to confirm these observations in the context of a larger randomised trial, since the amphotericin and intralipid combination was not licensed by health authorities and its feasibility and safety inadequately evaluated. ${ }^{17}$

Renal toxicity, potassium loss, fever, and chills were evident in both of our study arms. A reduced cumulative need for potassium supplementation was confounded by differences in individual diuretic treatment and did not translate into a decreased incidence of cardiac arrhythmia. The prospective analysis of various measures of feasibility and toxicity did not show a clinically relevant or statistically significant advantage of the lipid emulsion, and questionnaire data did not indicate a subjective benefit for our patients. Though the study had to be stopped prematurely for patient safety, the statistical power of our data was good enough to

Table 5 Prospective trials comparing toxicity of amphotericin B in glucose or intralipid

\begin{tabular}{|c|c|c|c|}
\hline Authors & $\begin{array}{l}\text { Underlying disease } \\
\text { (No of patients) }\end{array}$ & Infection treated & Preparation and administration of amphotericin B in intralipid \\
\hline Chavanet et $\mathrm{al}^{12}$ & HIV positive (22) & Oral candidiasis & $\begin{array}{c}1.0 \mathrm{mg} / \mathrm{kg} / \text { day amphotericin B (mixed directly with intralipid } 20 \% \text { ) as } \\
1 \text { hour intravenous infusion for } 4 \text { days }^{*}\end{array}$ \\
\hline Moreau et al ${ }^{13}$ & Tumour (32) & Fever of unknown origin & $\begin{array}{l}0.7-1.0 \mathrm{mg} / \mathrm{kg} / \text { day amphotericin B (dissolved in glucose then mixed with } \\
\text { intralipid } 20 \% \text { ) as a } 4 \text { hour intravenous infusion for } 11 / 18 \text { days }^{*}\end{array}$ \\
\hline Caillot et $\mathrm{al}^{14}$ & $\begin{array}{l}\text { Haematological disorders } \\
\text { (42) }\end{array}$ & Fever or documented mycosis & $\begin{array}{c}1.0-1.1 \mathrm{mg} / \mathrm{kg} / \text { day amphotericin B (mixed directly with intralipid } 20 \% \text { ) as } \\
\text { a } 2 \text { hour intravenous infusion for } 8 / 12 \text { days }^{\star}\end{array}$ \\
\hline Thakur $^{8}$ & Kala-azar (22) & Visceral leishmaniasis & $\begin{array}{l}0.05-1.0 \mathrm{mg} / \mathrm{kg} / \text { day amphotericin } \mathrm{B} \text { (dissolved in water then mixed with } \\
\text { intralipid } 10 \% \text { ) as a } 2-4 \text { hour intravenous infusion until dose of } \\
20 \mathrm{mg} / \mathrm{kg} \text { reached }\end{array}$ \\
\hline Schoffski et al & Tumour (51) & $\begin{array}{l}\text { Fever of unknown origin or } \\
\text { pneumonia }\end{array}$ & $\begin{array}{c}0.75 \mathrm{mg} / \mathrm{kg} / \text { day amphotericin B (Moreau type preparation) as a } 1-4 \text { hour } \\
\text { intravenous infusion for } 15 / 13 \text { days }{ }^{\star \star}\end{array}$ \\
\hline
\end{tabular}

* Significant reduction of amphotericin B related side effects such as renal toxicity, fever, or chills.

${ }^{*}$ Significant increase in pulmonary toxicity without evidence of renal protection or improved subjective tolerance. 
provide strong evidence that, in contrast with other observations, intralipid did not reduce the toxicity of amphotericin.

Pulmonary toxicity from conventional amphotericin is rare and usually related to bronchospasms or acute febrile reactions during the early phase of treatment. Respiratory distress with sudden dyspnoea, hypoxaemia, haemoptysis, and interstitial infiltrates has been observed in patients treated simultaneously with granulocyte transfusions. ${ }^{18}$ Severe dyspnoea, agitation, and chest tightness did occur in patients treated with liposomal amphotericin. ${ }^{19}$ Pulmonary events have never been reported in patients receiving amphotericin and intralipid. They were, however, frequent in our trial and unrelated to granulocyte transfusions, underlying medical conditions, or known risk factors. A significant weakness of this study is that pulmonary toxicity was not evaluated in a highly standardised manner. Blood-gas analysis or measurement of peripheral oxygen saturation was not routinely done, as there was no reported evidence of potential respiratory events. Bedside tests were performed only in patients with pulmonary distress. Because of the sudden, transient nature of the symptoms, however, a routine evaluation might not have been helpful. The interpretation of our pulmonary toxicity data is biased by the fact that pneumonia by chance was more common in the intralipid arm, although this difference was not statistically significant.

The temporal relation between the infusion of amphotericin in intralipid and the clinical manifestation of pulmonary symptoms suggests a causal association. The respiratory events were most likely related to the unconventional use of intralipid, or its incompatibility with amphotericin.

Several studies have reported varying intensity of pulmonary dysfunction when fat emulsions were given to seriously ill patients. ${ }^{20}$ In septicaemic patients rapid infusions of intralipid induce temporary, dose dependent changes in diffusion capacity and arterial oxygenation and an increase in pulmonary artery pressure. Short term infusions of intralipid $10-20 \%$ at a rate of $1-4 \mathrm{ml} / \mathrm{min}$ do result in a transient decrease in pulmonary diffusion capacity, even in healthy volunteers. ${ }^{21}{ }^{22}$ For this reason, although not exclusively, nutrition based on soya bean oil is given cautiously as a 12-24 hour infusion. A more specific complication is the fat overload syndrome, a rare condition related to repeated infusions of concentrated soya bean oil preparations, and associated with variable end organ dysfunction. This syndrome can present clinically with cough, dyspnoea, tachypnoea, or cyanosis, but has never been reported with antimycotic treatment. ${ }^{23}{ }^{24}$

The pulmonary toxicity could have also been related to an interaction between intralipid and amphotericin. The product information of intralipid highlights the increased risk of incompatibility with other drugs. None of the manufacturers of soya bean oil solutions, including the manufacturer of intralipid, recommends the use of lipid amphotericin. On the basis of theoretical considerations, clinical observations, and several recent pharmacological studies, amphotericin and intralipid should be regarded chemically incompatible. Several different concentrations of amphotericin in either intralipid 10 or $20 \%$ or other soya bean oil solutions, and both the Caillot and

\section{Key messages}

- Intralipid does not decrease the renal toxicity and subjective side effects associated with intravenous amphotericin B at a dose of $0.75 \mathrm{mg} / \mathrm{kg} /$ day in neutropenic cancer patients

- Use of amphotericin B in intralipid 20\% can be associated with transient pulmonary toxicity, possibly related to fat overload

- $250 \mathrm{ml}$ of intralipid $20 \%$ should not be given as a short term infusion or mixed with agents other than those recommended by the manufacturer

- On the basis of published data, amphotericin B and intralipid 20\% should be regarded as chemically incompatible

- The combination of amphotericin B and intralipid should not be given to patients

Moreau type of emulsion, have been studied under various experimental conditions. ${ }^{25}$ Amphotericin lipid mixtures are unstable, show an increase in particle size in emulsion over a short period, and do precipitate. Patients are therefore at risk of discontinuous administration of amphotericin, and possibly embolism. Self made lipid emulsions of amphotericin B should be regarded as unsafe until more pharmacological data are available.

The antimycotic efficacy of amphotericin B in intralipid is another controversial issue. Some evidence shows activity of this combination against superficial infections like HIV associated oropharyngeal candidiasis, or candidaemia in neutropenic cancer patients. The antimycotic activity of the lipid emulsion in systemic organ mycosis caused by candida or aspergillus, however, is still unproved.

\section{Conclusions}

Amphotericin and intralipid should be regarded as a highly experimental drug combination with an unclear pharmacological profile, unproved antimycotic efficacy, and potential risks. On the basis of the findings of our prospective randomised phase II study and a review of the current literature we conclude that the use of amphotericin in intralipid is not an acceptable way to give the antifungal agent to neutropenic cancer patients.

We thank Antje Luttmann and Radoslaw Kowalski for their help with the data acquisition and analysis, and Dr Ulrike Rapp-Bernhard, Department of Diagnostic Radiology, Hannover University Medical School, for independently reviewing all $x$ ray films and computed tomograms. Parts of this work were presented orally at the 36th interscience conference on antimicrobial agents and chemotherapy, 1996, New Orleans, Louisiana (organised by the American Society of Microbiology). Other parts were presented orally and as a poster at the 8th European congress of clinical microbiology and infectious diseases, 1997, Lausanne, Switzerland (organised by the European Society of Clinical Microbiology and Infectious Diseases).

Contributors: PS had the original idea for this study, prepared, coordinated, performed, and analysed the clinical trial, and wrote the paper; he will act as guarantor for the paper. MF coinitiated the research, discussed the study hypothesis, and participated in the protocol design. RW was responsible for data acquisition, documentation, and analysis, and contributed to the paper. DP helped with the interpretation of clinical chemistry data. CHK was involved in the treatment of study patients and discussed the main study results. $\mathrm{HH}$ was responsible for the statistical design and the power calculation. US did the statistical analysis. AG discussed core ideas, gave an interpretation of the findings, and contributed to the paper.

Funding: None.

Conflict of interest: None. 
1 Lyman CA, Walsh TJ. Systemically administered antifungal agents. A review of their pharmacology and therapeutic applications. Drugs 1992;44:9-35.

2 Khoo SH, Bond J, Denning DW. Administering amphotericin B-a practical approach. J Antimicrob Chemother 1994;33:203-13.

3 Kirsh R, Goldstein R, Tarloff J, Parris D, Hook J, Hanna N, et al. An emulsion formulation of amphotericin B improves the therapeutic index when treating systemic murine candidiasis. J Infec Dis 1988;158:1065-70. when treating systemic murine candidiasis. J Infec Dis 1988;158:1065-70.
4 Joly V, Farinotti R, Saint-Julien L, Cheron M, Carbon C, Yeni P. In vitro renal toxicity and in vivo therapeutic efficacy in experimental murine cryptococcosis of amphotericin B (fungizone) associated with intralipid. Antimicrob Agents Chemother 1994;38:177-83.

5 Caillot D, Chavanet P, Casasnovas O, Solary E, Zanetta G, Buisson M, et al. Clinical evaluation of a new lipid-based delivery system for intravenous administration of Amphotericin B. Eur J Clin Microbiol Infect Dis 1992;11:722-5.

6 Caillot D, Casasnovas O, Solary E, Chavanet P, Bonnotte B, Reny G, et al. Efficacy and tolerance of an amphotericin B lipid (intralipid) emulsion in the treatment of candidaemia in neutropenic patients. J Antimicrob Chemother 1993;31:161-9.

7 Macedo MCMA, Dulley FL, Ostronoff M, Machado CM, Zambon E, Masumoto C, et al. Effectiveness of amphotericin B in lipid emulsion for treating fungal septicemia in granulocytopenic patients. Clin Infec Dis 1994;19:366-7.

8 Thakur CP. Comparison of glucose versus fat emulsion in the preparation of amphotericin B for use in kala-azar. Trans $R$ Soc Trop Med Hyg 1994;88:698-9.

9 Anderson RP, Clark DA. Amphotericin B toxicity reduced by administration in fat emulsion. Ann Pharmacother 1995;29:496-500.

10 Joly V, Geoffray C, Reynes J, Goujard C, Méchali D, Maslo C, et al. Amphotericin B in a lipid emulsion for the treatment of cryptococcal meningitis in AIDS patients. J Antimicrobiol Chemother 1996;38:117-26.

11 Villani P, Regazzi MB, Maserati R, Viale P, Alberici F, Giacchino R. Clini$\mathrm{cal}$ and pharmacokinetic evaluation of a new lipid-based delivery system of amphotericin B in AIDS patients. Arzneimittelforschung 1996;46:445-9.

12 Chavanet PY, Garry I, Charlier N, Caillot D, Kisterman JP, D’Athis M, et al. Trial of glucose versus fat emulsion in preparation of amphotericin for use in HIV infected patients with candidiasis. $B M J$ 1992:305:921-5.

13 Moreau P, Milpied N, Fayette N, Rameé JF, Harousseau JL. Reduced renal toxicity and improved clinical tolerance of amphotericin B mixed with intralipid compared with conventional amphotericin B in neutropenic patients. J Antimicrob Chemother 1992;30:535-41

14 Caillot D, Reny G, Solary E, Casasnovas O, Chavanet P, Bonnotte B, et al. A controlled trial of the tolerance of amphotericin $\mathrm{B}$ infused in dextrose or in intralipid in patients with haematological malignancies. J Antimicrob Chemother 1994;33:603-13.

15 Meyer P, Adam D, Hiddemann W, Link H, Maschmeyer G, Helmerking M. Interventionstherapie von Infektionen und Fieber unklarer Genese bei neutropenischen Patienten mit malignen hämatologischen Grunderkrankungen-Studie II. Zeitschrift für antimikrobielle antineoplastische Chemotherapie 1992;10:1-27.

16 Bodey G, Bueltmann B, Duguid W, Gibbs D, Hanak H, Hotchi M, et al. Fungal infections in cancer patients: an international autopsy survey. Eur Clin Microbiol Infec Dis 1992;11:99-109.

17 Schöffski P, Luttmann A, Petersen D, Schumann G, Rapp-Bernhardt U, Freund M. Amphotericin B-neue Darreichungsform eines bewährten Antimykotikums. Arzneimitteltherapie 1994;12:115-7.

18 Wright DG, Robichaud KJ, Pizzo PA, Deisseroth AB. Lethal pulmonary reactions associated with the combined use of amphotericin $\mathrm{B}$ and leukocyte transfusions. N Engl J Med 1981;304:1185-9.

19 Arning M, Heer-Sonderhoff AH, Wehmeier A, Schneider W. Pulmonary toxicity during infusion of liposomal amphotericin $\mathrm{B}$ in two patients with acute leukemia. Eur J Clin Microbiol Infec Dis 1995;14:41-3.

20 Lindholm M. The ability of critically ill patients to eliminate fat emulsions. J Drug Dev 1991;4(Suppl 3):40-2.

21 Sundström G, Zauner CW, Arborelius M. Decrease in pulmonary diffusion capacity during lipid infusion in healthy men. J Appl Physiol 1973;34:816-20.

22 Greene HL, Hazett D, Demaree R. Relationship between intralipidinduced hyperlipidemia and pulmonary function. Am J Clin Nutr 1976;29:127-35.

23 Belin RP, Bivins BA, Jona JZ, Young VL. Fat overload with a 10\% soybean oil solution. Arch Surg 1976;111:1391-9.

24 Wesson DE, Rich R, Zlotkin SH, Pencharz PB. Fat overload syndrome causing respiratory insufficiency. J Pediatr Surg 1984;19:777-8.

25 Heide PE, Hohenberger $\mathrm{H}$. Tensiometrische und konduktometrische Stabilitäts- untersuchungen von Amphotericin B in Fettemulsionen. Österreichische Krankenhaus Pharmazie 1996;10:36-43.

(Accepted 5 May 1998)

\title{
Perinatal death associated with planned home birth in Australia: population based study
}

\author{
Hilda Bastian, Marc J N C Keirse, Paul A L Lancaster
}

PO Box 569,

Blackwood SA

5051, Australia

Hilda Bastian,

consumer advocate

Department of

Obstetrics and

Gynaecology,

Flinders University

of South Australia,

Flinders Medical

Centre, GPO Box

2100, Adelaide SA

5100, Australia

Marc J N C Keirse,

professor

Australian Institute of Health and

Welfare, National

Perinatal Statistics

Unit, University of

New South Wales,

NSW 2052,

Australia

Paul A L Lancaster, associate professor

Correspondence to: Ms Bastian

hilda.bastian@

flinders.edu.au

BMJ 1998;317:384-8

\begin{abstract}
Objective: To assess the risk of perinatal death in planned home births in Australia.

Design: Comparison of data on planned home births during 1985-90, notified to Homebirth Australia, with national data on perinatal deaths and outcomes of home births internationally.

Results: 50 perinatal deaths occurred in 7002 planned home births in Australia during 1985-90: 7.1 per 1000 (95\% confidence interval 5.2 to 9.1$)$ according to Australian definitions and 6.4 per 1000 (4.6 to 8.3) according to World Health Organisation definitions. The perinatal death rate in infants weighing more than $2500 \mathrm{~g}$ was higher than the national average (5.7 versus 3.6 per 1000: relative risk $1.6 ; 1.1$ to 2.4 ) as were intrapartum deaths not due to malformations or immaturity ( 2.7 versus 0.9 per 1000 : $3.0 ; 1.9$ to 4.8$)$. More than half $(52 \%)$ of the deaths were associated with intrapartum asphyxia.

Conclusions: Australian home births carried a high death rate compared with both all Australian births and home births elsewhere. The two largest contributors to the excess mortality were underestimation of the risks associated with post-term birth, twin pregnancy and breech presentation, and a lack of response to fetal distress.
\end{abstract}

\section{Introduction}

Despite decades of political and academic debate the relative merits of home versus hospital birth remain unproved. This is likely to remain so. Comparisons that are sufficiently unbiased and large enough to address crucial safety issues are unlikely to be forthcoming. ${ }^{12}$ Although home and hospital offer different risks and benefits for births, neither has standard care characteristics. In fact the range from safe to unsafe practice may be wider within each location than it is between them. Addressing what constitutes safe birth practice at home may be a more pivotal concern than attempting to quantify the theoretical differences attributable to place of birth.

In the Netherlands, where $30 \%$ of births are planned to be at home, there is a widely accepted list of criteria for home birth. ${ }^{3}$ When home birth is uncommon, opinions and practice can vary more widely. Thus leaflets on informed choice of place of birth in the United Kingdom do not specify any contraindications to home birth. ${ }^{45}$ Others have advocated home birth for women at high risk of obstetric complications, ${ }^{67}$ and trends to abandon risk assessment for home birth are apparent in both Australia $^{8}$ and the United States. ${ }^{9}$ 